\title{
VARIATIONS IN GEOTECHNICAL CHARACTERISTICS OF SOME CRUDE OIL CONTAMINATED SOILS
}

IBRAHIM ADEWUYI OYEDIRAN AND NCHEWI IDEBA ENYA

(Received 21 April 2020; Revision Accepted 25 May 2020)

\begin{abstract}
Variations based on the effects of curing time and environmental exposures on the geotechnical characteristics of some crude oil contaminated soils were investigated. 2 to $10 \%$ by weight of crude oil was added to soils as a simulation of contamination. The contaminated soils were cured under room temperature (unexposed) as well as outside in the open air (exposed) for 21, 63 and 189 days. Geotechnical, geochemical and mineralogical analyses were carried out on the contaminated and uncontaminated soil samples. Results indicate that for the unexposed soils, the $\mathrm{LL}$ and PL increased as crude oil concentration (COC) increased up to $4 \%$, above which both decrease. But the reverse was the case for $\mathrm{PI}$ after curing for 21 days. With increasing curing time to 63 and 189 days, LL and PL both increased with increase in COC while PI decreased. The UCS increased with increase in oil content up to $4 \%$, but decreased as oil content increased above $4 \%$. Furthermore, UCS decreased with increase in curing time. Across all curing periods, MDD increased upon addition of crude oil up to $4 \%$, thereafter it decreased with increase in COC. The hydraulic conductivity decreased with increase in COC and curing time. For the exposed soils, LL, PL and PI all increased upon addition of crude oil up till $4 \%$ before decreasing as the amount of oil increased above $4 \%$ for the curing duration of 21 days. For 63 and 189 days, LL and PL decreased while PI increased. Maximum dry density (MDD) showed same variation trend in exposed soils similar to that shown by the unexposed soils. Hydraulic conductivity increased with increase in COC and curing time. Thus, crude oil is observed to be capable of altering the geotechnical properties of soils exposed to it. Furthermore, contaminated soils exposed to the open air and longer curing time were significantly modified than the unexposed variant and with reduced exposure time.
\end{abstract}

KEYWORDS: Geotechnical variation, Contamination, Curing environment, Curing time, Exposure

\section{INTRODUCTION}

Hydrocarbon pollution of soil can occur in several ways, from natural seepage in areas where petroleum is found in shallow reservoirs, to accidental spillage of crude oil. Nigeria experiences a high frequency of oil spills in different parts of the country, and most of the cases of crude oil contamination in Nigeria especially in the Niger Delta region are caused by sabotage and negligence (Otunyo, 2010). According to lloeje and Aniago (2016), crude oil has been implicated as a major source of contamination resulting in building failure owing to the reduction in some critical geotechnical properties of the contaminated soil. Yaji et al. (1997) reported that the failure of three industrial buildings in India was due to large settlements of soil caused by accidental spillage. Furthermore, the presence of crude oil contaminated layer under footings results in decrease in bearing capacity ratio (CBR) and increase in settlement.

Several research efforts to investigate the effects of hydrocarbon on the engineering characteristics of soils have been undertaken. Evgin et al. (1992) performed a series of triaxial tests on contaminated and uncontaminated clean sands with results showing that the oil-saturated samples drastically reduced the friction angle for loose and dense samples while it apparently increased the volumetric strain. These findings also suggested that settlement of footing would increase as a result of oil contamination. Shin et al. (1997) studied the load capacity for oil partially saturated sand at oil content up to $6 \%$ with results indicating drop in load capacity with increase of oil content. Investigations into the effect of crude oil on geotechnical properties of sandy soil and clay by Khamehchiyan et al. (2007) showed that the Atterberg limits decreased with the increase in oil percentage while increase in oil content also caused decrease in maximum dry density, optimum water content, porosity and shear strength. Adejumo (2012) studied the effects of crude oil contamination on the geotechnical properties of soft clay soils of Niger Delta region of Nigeria. The laboratory investigations carried out on the soil - crude mixtures indicated that the crude oil caused $17.9 \%$ increase in the Liquid limit, $6.9 \%$ increase in the plastic limit and $37.5 \%$ increase in the plasticity index. A corresponding increase in bulk density with increase in sorption time was observed.

Ibrahim Adewuyi Oyediran, Department of Geology, University of Ibadan, Ibadan, Nigeria.

Nchewi Ideba Enya, Department of Geology, University of Ibadan, Ibadan, Nigeria. 
However, the porosity, and swelling pressure of the contaminated soils decreased with increase in both sorption time and crude oil content, while the undrained shear strength of the soils fluctuated. Ojuri and Ogundijo (2012) worked on 'Modeling Used Engine Oil Impact on the Compaction and Strength Characteristics of a Lateritic Soil'. Their study simulated an oil contaminated site by mixing $2,4,6,8$ and $10 \%$ of used engine oil by dried weight of the soil with lateritic soil samples collected in Akure, Southwestern Nigeria. The oil contaminated soils indicated lower Maximum Dry Density (MDD), Optimum Moisture Content (OMC), Unconfined Compressive Strength (UCS) and California Bearing Ratio (CBR) compared to the uncontaminated soil. Regressive models for the estimation of compaction and strength characteristics for this type of ferrallitic lateritic soils were established. Jonathan (2013) also carried out a laboratory based experiment to find out the effect of light crude oil contamination on the geotechnical properties of kaolinite clay soil. The contaminated soil was prepared by adding different percentages of the light crude oil $(2 \%, 5 \%, 8 \%, 10 \%$, $15 \%$ and $20 \%$ ) measured by weight of the dry soil sample and thoroughly mixed until a uniform state of mixture was achieved. The classification results showed that crude oil contamination caused an increase in linear shrinkage, liquid limit, plastic limit and plasticity index between $0 \%$ to $20 \%$ contaminations. The compaction result showed that there was an increase in maximum dry density while the optimum moisture content decreased between $0 \%$ and $15 \%$ of crude oil contamination. It was observed that the soil could not compact at $20 \%$ contamination and above. Also, the coefficient of permeability increased with increase in the percentage of crude oil contamination while the coefficient of consolidation value $(\mathrm{Cv})$ increases with increase in the percentage of contamination. There was a decrease in the cohesion value and the frictional angle due to the introduction of the crude oil into the soil. Ukpong et. al., (2015) studied the effects of oil spills on the geotechnical properties of lateritic soils in Okorete town, eastern Obolo Local Government Area of Akwa Ibom state, Nigeria. They collected soil samples from both the normal soil and contaminated area where there was oil spillage using hand auger. The samples were oven dried, and several geotechnical tests such as compaction, sieve analysis, California Bearing Ratio and Atterberg limits were carried out. They found out that there was a reduction in the percentage of fines with increase in the oil content. This was due to the oil which clogged to the different particles and prevents them from successfully passing through each stack of sieve. The optimum moisture content (OMC) and the Maximum dry density (MDD) reduced from $11.40 \%, 1.98 \mathrm{~g} / \mathrm{cm}^{3}$ to $9.50 \%, 1.81 \mathrm{~g} / \mathrm{cm}^{3}$ respectively. This was believed to have been caused by the crude oil content in the soil which coats and agglomerates the lateritic soil particles thereby reducing the specific surface area. This in turn leads to the reduction in the bonding strength of the soil. It was also observed that the liquid limit (LL) of the contaminated soil reduced from 29.00 to 16.04 and this was attributed to the alteration of the cohesive bonds and forces that exist between the particles of the soil. Similarly, there was a reduction in the California Bearing Ratio (CBR) values of the contaminated soils samples compared with the uncontaminated samples.

However, despite studies already undertaken by several researchers, not much has been done to understand the effects of curing time (ageing), curing environment (exposure) as well as variation in oil content (quantity) on the geotechnical properties of the oil contaminated soils. Therefore, this study investigates the variations in geotechnical characteristics of crude oil contaminated soils under different curing and environmental conditions in addition to the quantity involved.

\section{MATERIALS AND METHODS}

Clay soil samples were collected from Omi-Adio, southwestern Nigeria at $1.0 \mathrm{~m}$ depths in trial pits established for that purpose (Fig. 1). Index properties including consistency limits, grain size distribution and specific gravity of the soils were determined using BS 1377 (1990) standard test procedures. Furthermore, compaction, unconfined compressive strength (UCS), and permeability (using falling head permeameter) tests were also carried out prior to contamination of the soil. 


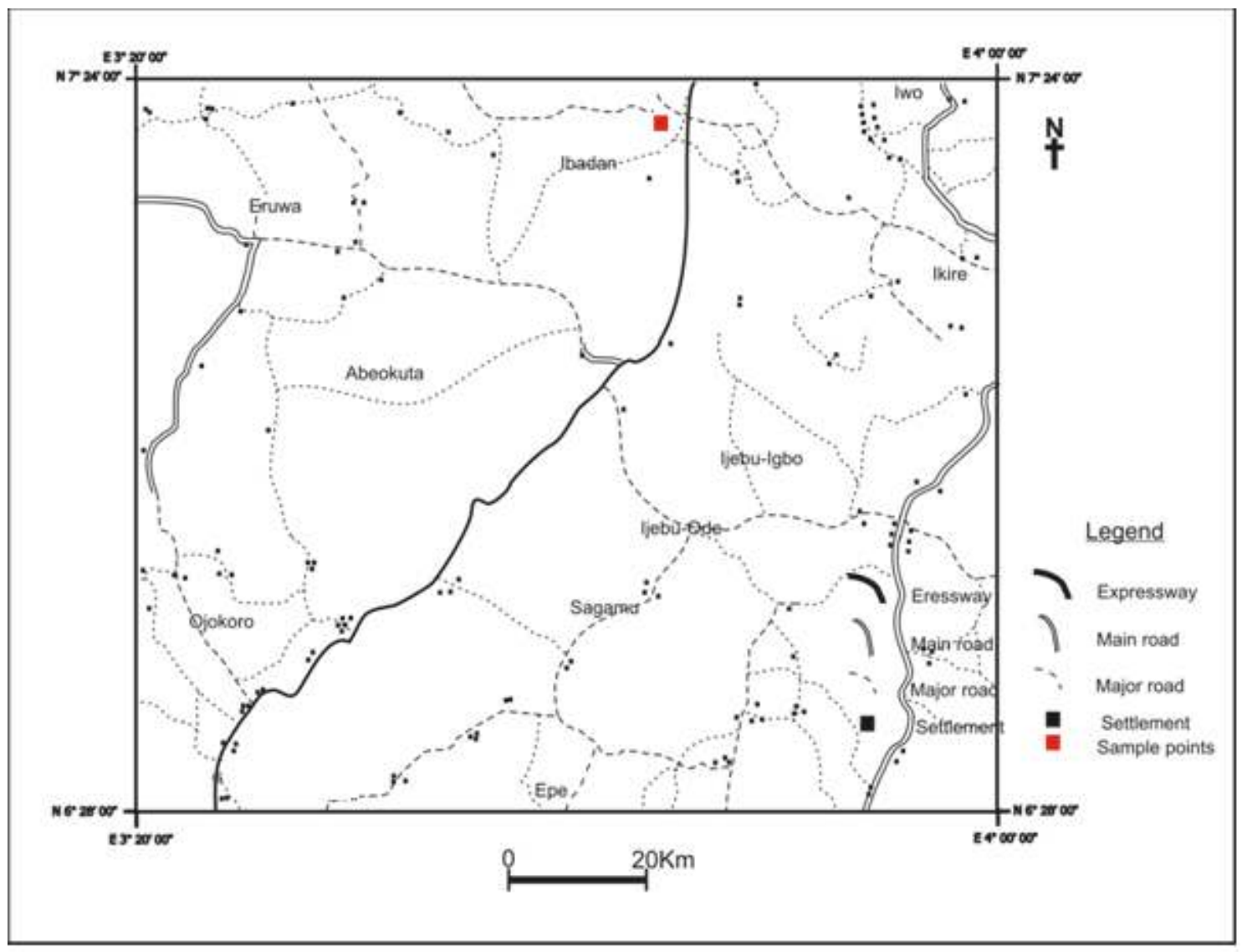

Fig. 1: Map of the study area

The contaminant (crude oil) used for this study was obtained from Bodo West field, Okrika, Rivers state, Nigeria. The physiochemical properties of the crude oil are presented in Table 1 . The contaminant is classified as light crude according to the America Petroleum Institute (2011) since it has an API gravity value of
37.78. America Petroleum Institute (2011) classified crude oil samples greater than 31 as light crude. Crude oil sample are classified as sweet if its sulphur content is less than $0.5 \%$ and as sour if its sulphur content is greater than $0.5 \%$. With reference to the sulphur content, the contaminant is sweet crude

Table 1: Properties of crude oil (Oyediran and Enya, 2020)

\begin{tabular}{|c|c|c|c|c|c|}
\hline Contaminant & $\begin{array}{l}\text { Specific } \\
\text { Gravity }\end{array}$ & $\begin{array}{l}\text { Viscosity at } \\
40^{\circ} \mathrm{c} \text { (cst) }\end{array}$ & $\begin{array}{l}\text { Sulphur Content } \\
\text { (\%wt) }\end{array}$ & $\begin{array}{l}\text { API Gravity } \\
(\mathrm{gm} / \mathrm{ml})\end{array}$ & $\begin{array}{l}\text { Pour } \\
\text { Point }\left({ }^{0} \mathrm{c}\right)\end{array}$ \\
\hline Crude oil & 0.8359 & 2.5 & 0.139 & 37.78 & 0.91 \\
\hline
\end{tabular}

2, 4, 8 and 10 percent by weight of crude oil was mixed thoroughly with the soil samples as a simulation of spillage and allowed to cure for 21, 63 and 189 days in order to determine its long term effects on the soil. A set of twelve contaminated samples was cured in the open (exposed) to atmospheric conditions, while the second set (12) was cured under room temperature (unexposed) in the laboratory under room temperature. The mineralogical and chemical compositions of the soil were determined using the X-ray diffraction $(X R D)$ and $X$-ray fluorescence (XRF) methods respectively at XRD Analytical and consulting cc, South Africa. After milling, the material was prepared for XRD analysis using a back loading preparation method. It was analysed with a PANalytical EMPyrean diffractometer with PIXcel detector and fixed slits with $\mathrm{Fe}$ filtered $\mathrm{Co}-\mathrm{Ka}$ radiation. The phases were identified using X'pert Highscore plus software. The relative phase amounts (weight \%) was estimated using the Rietveld method.

\section{RESULTS}

Summary of the results of the analyses carried out on the uncontaminated soil are presented in Table 2, while details of the contaminated soils (exposed and unexposed) can be found in Appendix 1 and 2.

\section{GRAIN SIZE DISTRIBUTION (GSD)}

The uncontaminated soil is a well graded soil consisting of gravel $(1.09 \%)$, sand $(16.88 \%)$, silt $(28.03 \%)$, clay (54.0\%) and high amount of fines (82.03\%).

\section{CLASSIFICATION}

The uncontaminated soil properties (Table 1.) Show that the soil is an inorganic clay soil of high plasticity $(\mathrm{CH})$, while based on AASHTO classification the soil 
falls under the A-7-5 group. The soil is well graded with high amount of fines.

\section{SPECIFIC GRAVITY AND NATURAL MOISTURE CONTENT}

Table 2: Summary of Uncontaminated soil Properties

\begin{tabular}{|c|c|c|}
\hline Characteristics & Parameter & $\begin{array}{l}\text { Uncontaminated } \\
\text { Soil }\end{array}$ \\
\hline \multirow{5}{*}{ Grain Size Distribution (\%) } & Gravel & 1.09 \\
\hline & Sand & 16.88 \\
\hline & Silt & 28.03 \\
\hline & Clay & 54.00 \\
\hline & Fines & 82.03 \\
\hline \multirow{3}{*}{ Consistency Limits (\%) } & Liquid Limit & 54.00 \\
\hline & Plastic Limit & 29.90 \\
\hline & Plasticity Index & 24.10 \\
\hline \multicolumn{2}{|c|}{ Natural Moisture Content (\%) } & 21.88 \\
\hline \multicolumn{2}{|l|}{ Specific Gravity } & 2.77 \\
\hline \multirow{2}{*}{ Classification } & USCS & $\mathrm{OH}$ \\
\hline & AASHTO & A-7-5 \\
\hline \multirow{2}{*}{ Compaction } & OMC (\%) & 20.50 \\
\hline & MDD (gm/cc) & 1.56 \\
\hline Permeability & $\mathrm{K}(\mathrm{cm} / \mathrm{s})$ & $9.73 \times 10^{-1}$ \\
\hline Strength & $\operatorname{UCS}\left(\mathrm{KN} / \mathrm{m}^{2}\right)$ & 4.15 \\
\hline \multirow{13}{*}{ Major Elements (\% g/g) } & $\mathrm{SiO}_{2}$ & 40.23 \\
\hline & $\mathrm{TiO}_{2}$ & 1.00 \\
\hline & $\mathrm{AlO}_{3}$ & 26.89 \\
\hline & $\mathrm{Fe}_{2} \mathrm{O}_{3}$ & 15.06 \\
\hline & $\mathrm{MnO}$ & 0.05 \\
\hline & $\mathrm{MgO}$ & 0.17 \\
\hline & $\mathrm{CaO}$ & 0.13 \\
\hline & $\mathrm{Na}_{2} \mathrm{O}$ & 0.11 \\
\hline & $\mathrm{K}_{2} \mathrm{O}$ & 0.07 \\
\hline & $\mathrm{P}_{2} \mathrm{O}_{5}$ & 0.03 \\
\hline & $\mathrm{Cr}_{2} \mathrm{O}_{3}$ & 0.03 \\
\hline & $\mathrm{SO}_{3}$ & $<0.01$ \\
\hline & LOI & 15.32 \\
\hline \multirow{4}{*}{ Trace Elements (mg/kg) } & $\mathrm{Cu}$ & 50.6 \\
\hline & $\mathrm{Ni}$ & 11.51 \\
\hline & $\mathrm{Pb}$ & 13.7 \\
\hline & $\mathrm{Zn}$ & 81.4 \\
\hline \multirow{4}{*}{$\begin{array}{l}\text { Mineralogical Composition } \\
(\%)\end{array}$} & Quartz & 4.83 \\
\hline & Hematite & 5.72 \\
\hline & Kaolinite & 93.42 \\
\hline & Anatase & 0.29 \\
\hline
\end{tabular}

\section{Consistency limits}

The presence of crude oil in the unexposed soil after curing for 21 days resulted in an increase in liquid limit $(\mathrm{LL})$ and plastic limit (PL) with increase in crude oil content (COC) up to $4 \%$, after which, both limits decreased. Meanwhile, the plasticity index (PI) decreased with addition of crude oil up to $4 \%$, after which it increased as COC increases. With increase in curing time to 63 days, the LL and PL increased further with increase in $\mathrm{COC}$ while the $\mathrm{PI}$ decreased.
The soil possesses specific gravity of 2.77 making it a potentially durable construction material, with a natural moisture content of $21.88 \%$. 


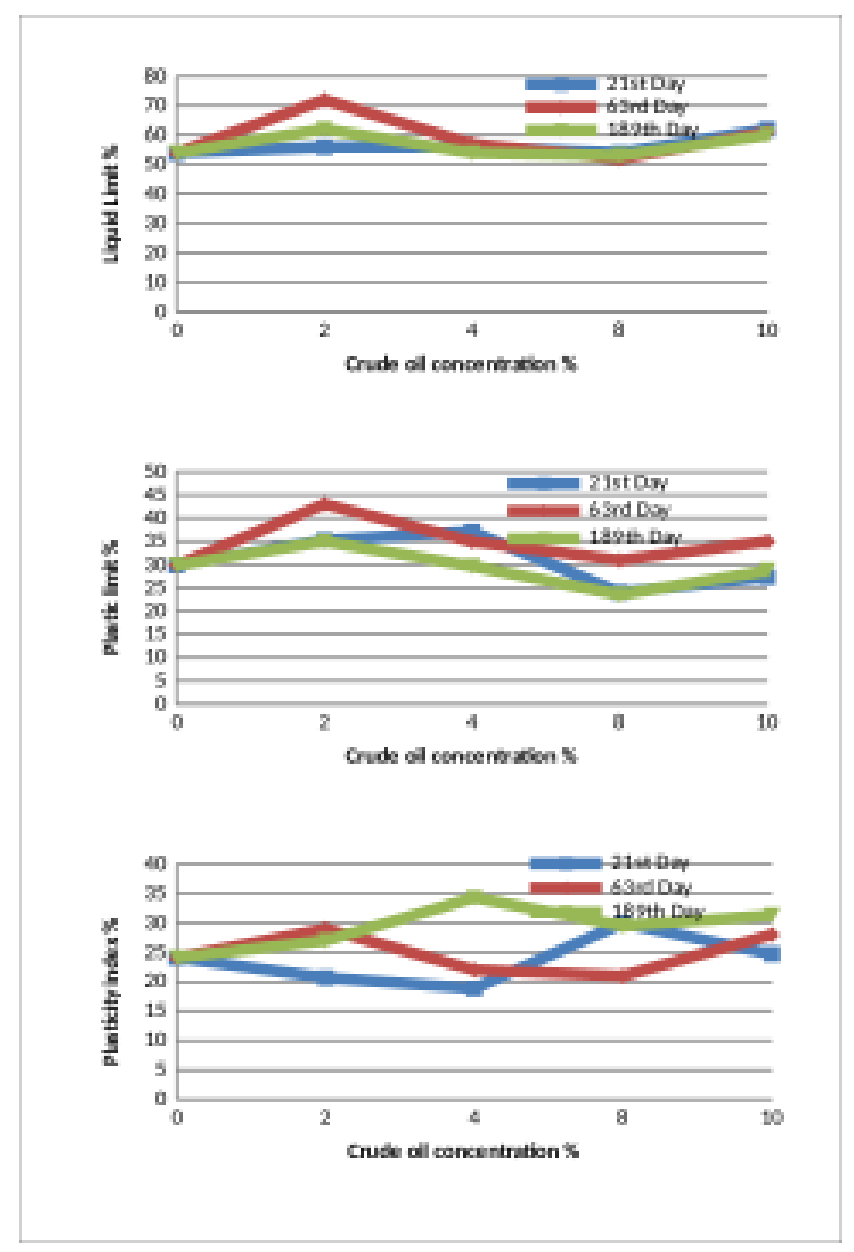

Fig. 2: Variations in Consistency limits of the unexposed soils

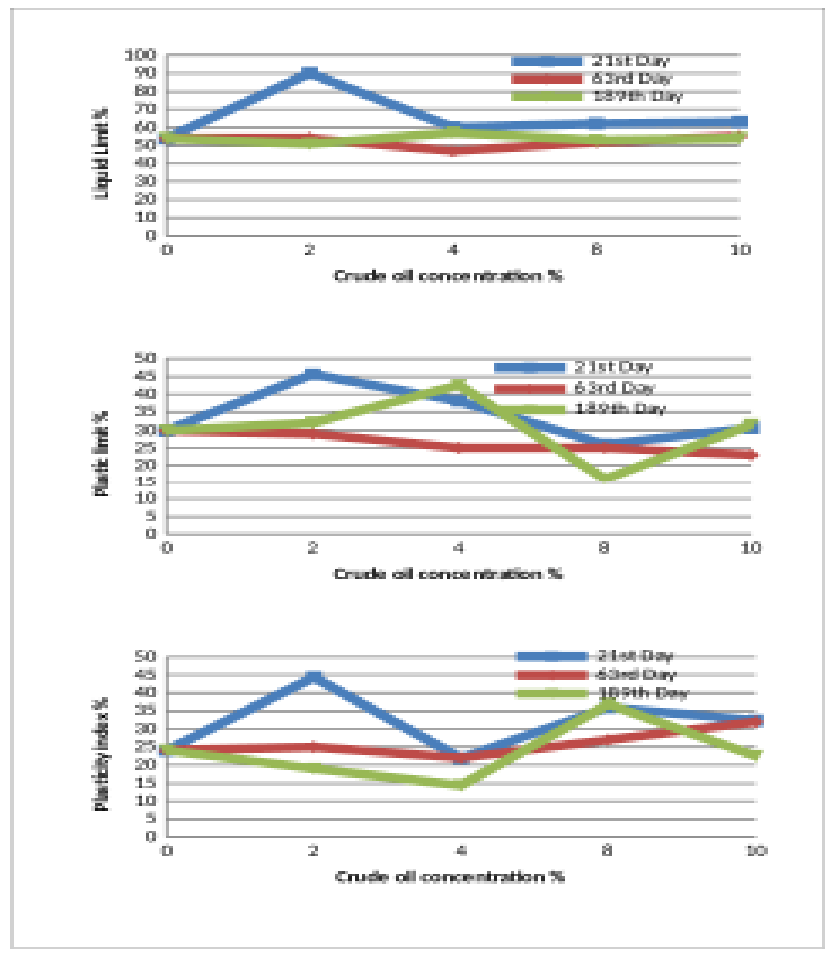

Fig. 3: Variations in Consistency limits of the exposed soil 


\section{COMPACTION CHARACTERISTICS}

The addition of crude oil up to $4 \%$ resulted in an initial increase in MDD across all curing periods, after which it decreased upon further addition of crude oil (8-10\%). This trend was noticed for both the unexposed (Fig. 4a) and exposed soils (Fig. 4b). Generally, at each percentage of contamination, the MDD tends to increase as the curing time increased. For the first curing period of 21 days for the unexposed soil, at 2 and $4 \%$ COC, the MDD increased at OMC of $18.3 \%$ and $19.3 \%$ respectively. As COC increased to 8 and $10 \%$, there was a drop in MDD at OMC of $18.7 \%$ and $14.3 \%$ respectively. Similarly, as the curing period increased to 63 days, with $2 \%$ and $4 \%$ crude oil added, the MDD increased at OMC of $23 \%$ and $19.5 \%$ respectively. With increase in oil content (8-10\%), MDD decreased at OMC of $20.7 \%$ and $21.3 \%$ accordingly. For 189 days, the
MDD at 2 and $4 \%$ COC also increased with OMC of $22 \%$ and $25 \%$ respectively. However, further increase in COC $(8-10 \%)$ resulted in a decrease in MDD with OMC of $24.4 \%$ and $20.2 \%$ respectively. For the exposed samples, MDD increased with OMC of $21 \%$ and $23 \%$ at $2 \%$ and $4 \%$ COC after 21 days of curing. Thereafter, it decreased at $8 \%$ and $10 \%$ COC with OMC of $21.6 \%$ and $21.3 \%$ respectively. With increase in curing time up to 63 days, MDD increased with OMC of $21.3 \%$, and $13.7 \%$, but later decreased with OMC of $21.7 \%$ and $20.3 \%$ respectively when $8 \%$ and $10 \%$ more of crude was added. Furthermore, as the oil-soil contact time reached 189 days, with $2 \%$ and $4 \%$ COC, MDD increased with OMC of $19 \%$ and $17.3 \%$ respectively. It then decreased upon further addition of crude oil (8\%$10 \%$ ) with OMC of $23 \%$ and $21 \%$ respectively.
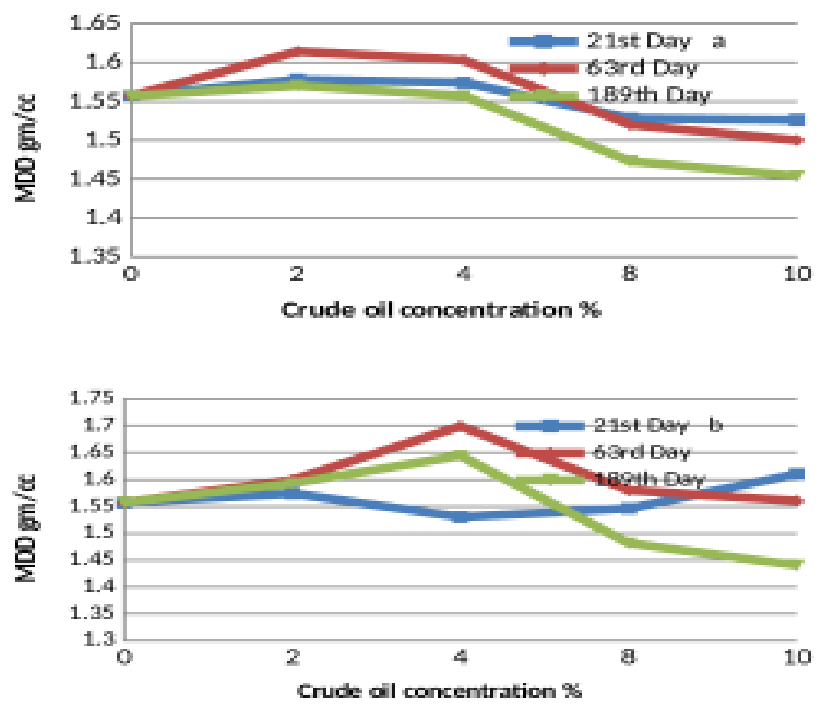

Fig. 4: Variations in MDD of the a) unexposed and b) exposed soils 
PERMEABILITY CHARACTERISTICS

The permeability or hydraulic conductivity $(\mathrm{HC})$ of the unexposed soils decreased with increase in concentration of crude oil and curing time (Fig. 5a). But increased as the curing time and oil content increased in the exposed
(Fig.

$5 b)$.
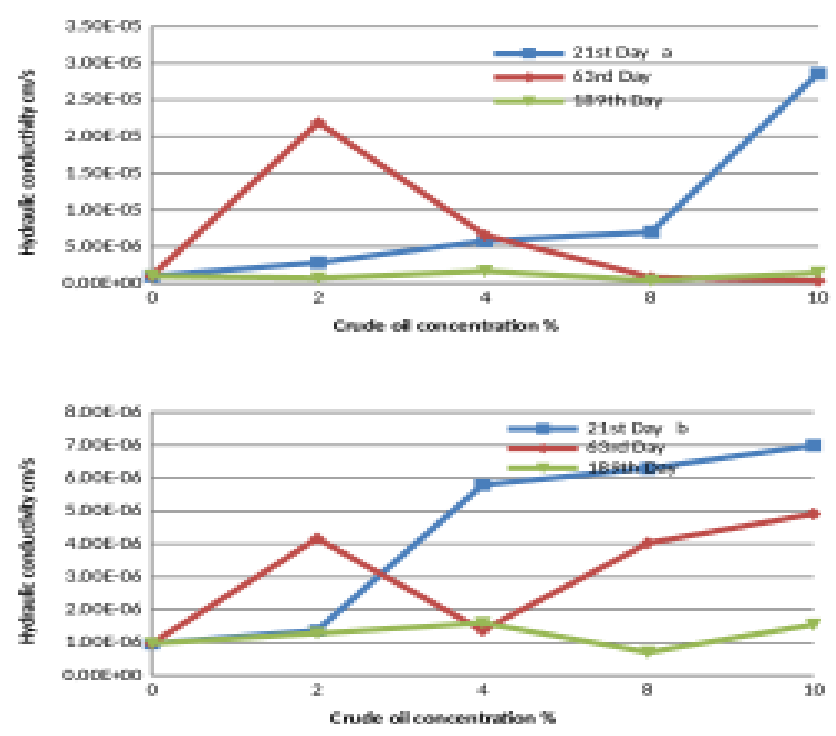

Fig. 5: Variations in Hydraulic conductivity of a) unexposed soils b) exposed soils

\section{STRENGTH CHARACTERISTICS}

The UCS of the unexposed samples increased with increased COC up till $4 \%$, after which it decreased with further increase in the COC. Furthermore, the UCS decreased as the curing duration increased (Fig. 6a). For the exposed soils, UCS increases with increase in $\mathrm{COC}$ and curing time (Fig. 6b).

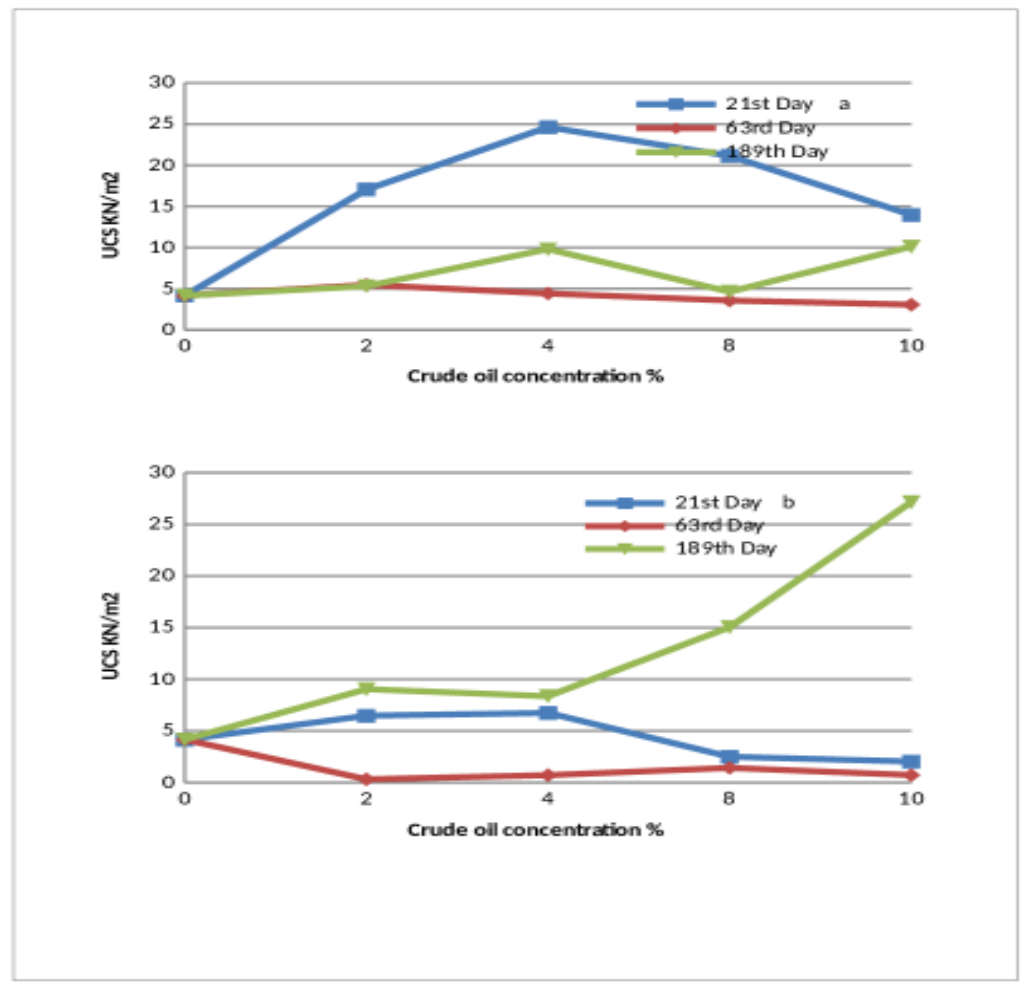

Fia. 6: Variations in Unconfined comnressive strenath of a) unexnosed soils b) exnosed soils 


\section{MINERALOGY}

Due to their mode of formation, clay minerals strongly reflect the character of their parent or source materials and the climatic conditions that existed during weathering (Friedman and Sanders, 1997). In terms of composition, the soil contains Quartz, Hematite, Kaolinite and Anatase (Fig. 7). Kaolinite (93.42\%) is the most abundant clay mineral in the soil. This composition makes the soil less reactive compared to soils composed of montmorillonite minerals (Broderick and Daniel, 1990). However, the addition of crude oil to the soils brought about changes in the mineralogy of the soils. Figure 8 shows representative diffractograms of unexposed and exposed contaminated soils.

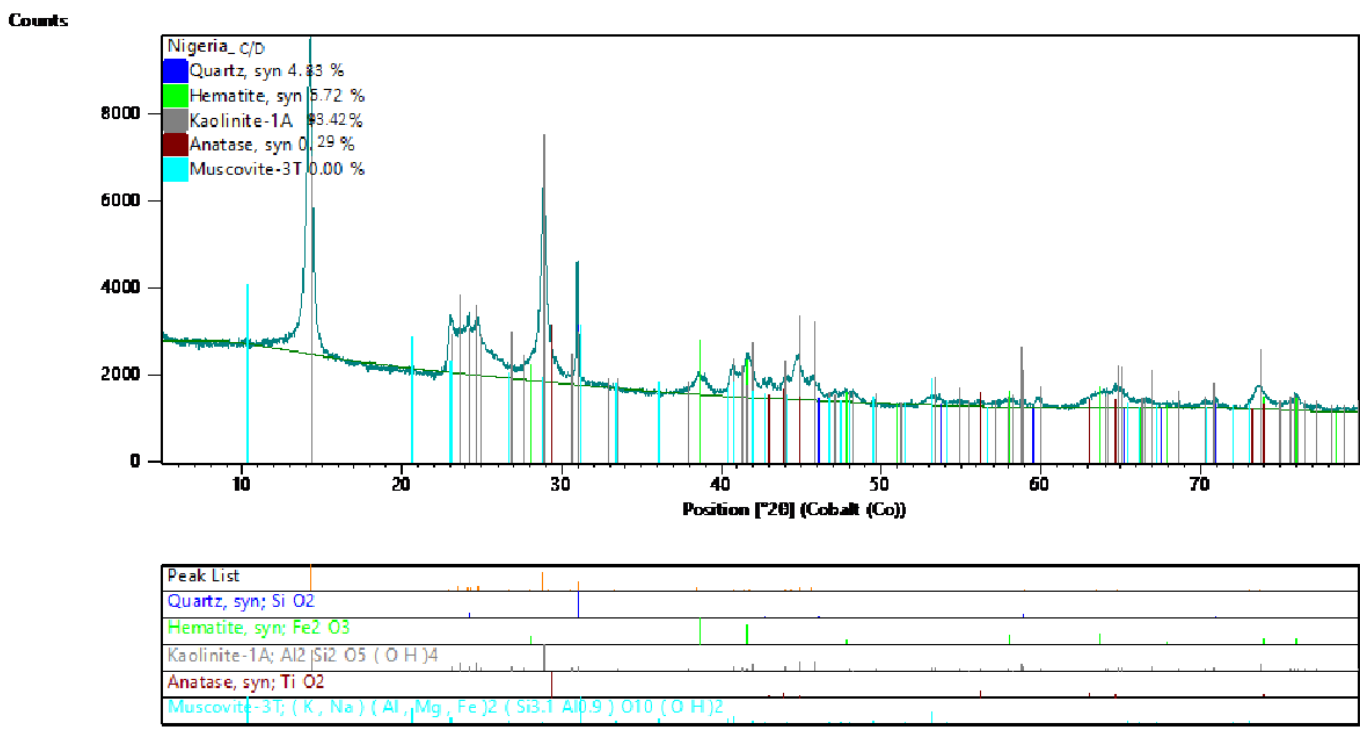

Fig. 7: Xray Diffractogram of uncontaminated soil
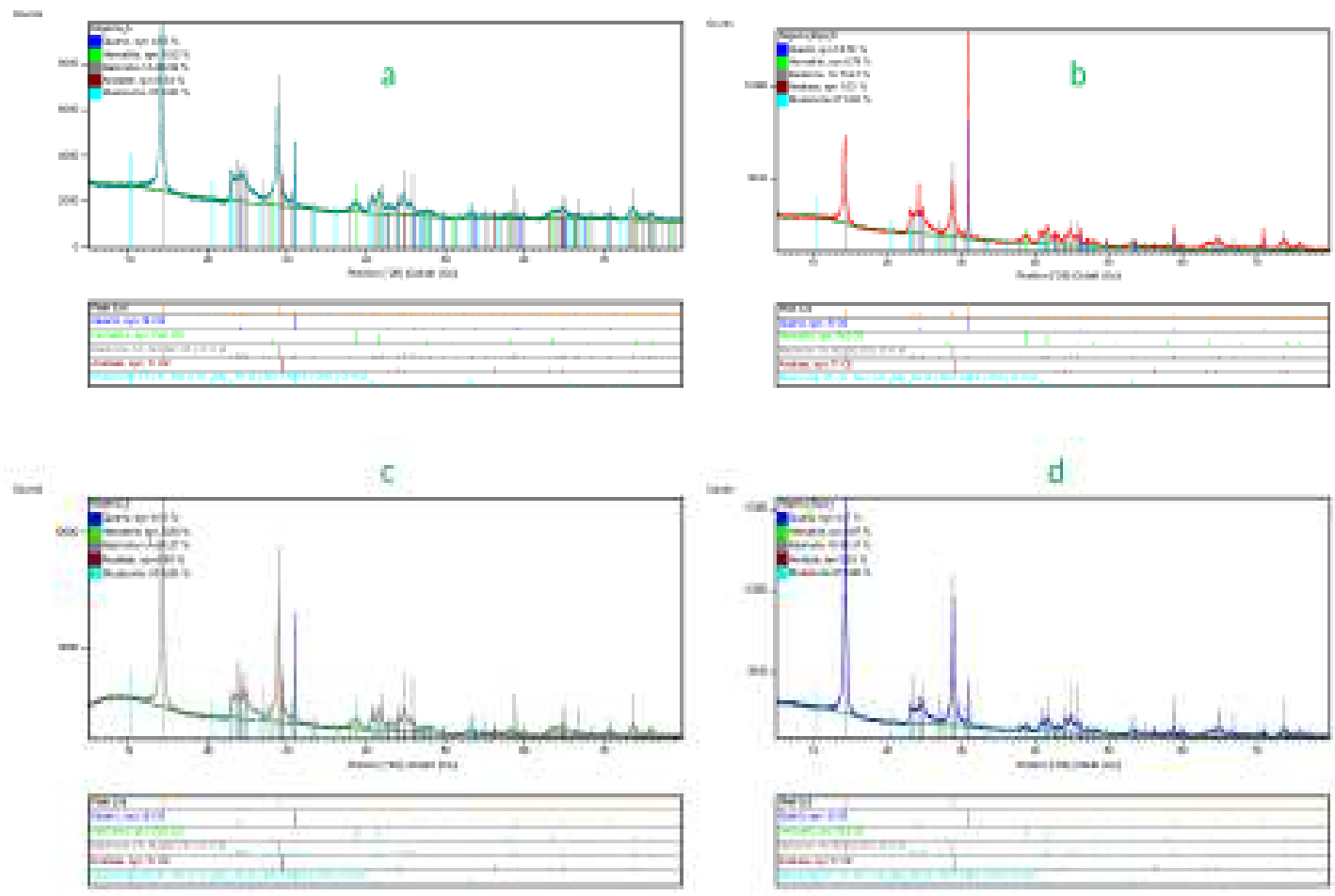

Fig. 8: Representative diffractograms of unexposed and exposed contaminated soils 


\section{CHEMICAL COMPOSITION}

The XRF analyses show $\mathrm{SiO}_{2}(40.23 \% \mathrm{~g} / \mathrm{g}), \mathrm{AlO}_{3}$ $(26.89 \% \mathrm{~g} / \mathrm{g})$, and $\mathrm{Fe}_{2} \mathrm{O}_{3}(15.06 \% \mathrm{~g} / \mathrm{g})$ as the abundant major elements while trace elements including $\mathrm{Cu}$ $(50.6 \mathrm{mg} / \mathrm{kg})$, Ni $(11.51 \mathrm{mg} / \mathrm{kg}), \mathrm{Pb}(13.7 \mathrm{mg} / \mathrm{kg})$, and $\mathrm{Zn}$ $(81.4 \mathrm{mg} / \mathrm{kg})$ are also present in the soil.

\section{DISCUSSION}

The plastic property of clayey soils is controlled by the orientation of water around the clay particles (Das, 1994). The presence of hydrocarbon, which is a nonpolarized liquid, acts like adsorbed water (i.e. with electrostatic effect and possible chemical interactions) and causes the reduction in the thickness of water film around clay minerals. Oluremi et al. (2017) mentioned that the addition of crude oil to the soil caused micro structural transformation of the soil, which leads to inter layer expansion within the clay minerals. According to Akinwumi et al. (2015), the increase in the LL of the soil is due to the presence of crude oil, which might have enveloped both the clay minerals of the soils and the adsorbed water bonded to its surfaces resulting in increase in $\mathrm{LL}$ and $\mathrm{PL}$.

Furthermore, the increase in LL is attributable to the dispersion of clay particles. Rao and Mathew (1995) stated that clay particles become dispersed when they interact with chemicals. Due to the dispersion and deflocculation of clay particles, the geotechnical properties of clays are significantly changed, hence the increase in the consistency limits of the soils. Meegoda and Ratnaweera (1994) also reported that fluid viscosity can affect the Atterberg limits of soils. Crude oil has higher viscosity than water; this high viscosity and surface tension would promote retention of oil between soil particles, hence the change in consistency limits values. Moreover, increase in PL could have been as a result of organic particles being absorbed on mineral surfaces of the soil thereby modifying both the properties of the soils and the organic material itself (Mitchel, 1976). According to Jonathan (2013), increase in $\mathrm{LL}$ and $\mathrm{PL}$ is accounted for by exchangeable or bond cations on the surface or inter - layer of clay particles due to the contamination. The presence of crude oil reduces amount of water and enhances cohesion. The extra cohesion provided to the clay soil by the crude oil also contributed to the increase in the liquid limit. The increase in PL also implies that the addition of crude oil into the soil altered the pore fluid chemistry and caused the replacement of cations resulting in physiochemical interactions between the soil particles. But as the percentage of crude oil increased above $4 \%$, the soil samples appear aggregated, resulting in decrease in the PL and LL observed after curing for 21 days. Jesna and Hari (2015) also suggested that the decrease in PL is due to the alteration of the cohesive bonds and forces that exist between the particles of the soils. Moreover, the PI initially decreased with addition of crude oil up to $4 \%$ after 21 days. However, further addition of crude oil (8 and 10\%) resulted in increase in the PI of the soils. In addition, as the curing period increased to 63 and 189 days, $\mathrm{PI}$ also decreased further. The decrease in $\mathrm{PI}$ is thought to be indicative of the problematic nature of clay soils.
In the exposed soils (Fig. 4), the LL, PL and PI after 21 days generally increased upon initial addition of crude oil to the soil. However, above $4 \%$ COC, the LL, PL and PI decreased. After curing for 63 days, the LL and PL decreased as COC increased while the PI increased at all percentages of contamination. A similar trend was observed as the curing time reached 189 days. Arasan (2010) noted that the definition of the geotechnical properties of clays at laboratory temperature is far from mimicking in-situ conditions. Besides the effect of the crude oil; exposing the soils to adverse weather conditions with ingress of sun, rainfall and excessive air also contributed to the variations in the consistency limits of the contaminated soils. Kurt et al. (2007) indicated that the LL of clayey soil decreased with increasing concentration and temperature of $\mathrm{NaCl}$ and $\mathrm{KCl}$ salt solution. These observed variations in response of the consistency limits in the exposed samples may also be attributable to effect of evaporation and moisture variation resulting from the rise and fall in the temperature of the environment and distribution of rainfall.

Moore and Mitchell (1994) attributed increase in shear strength of soil specimens contaminated by organic chemicals to the decrease in dielectric constant of the pore fluid. The initial increase in the strength of the soil samples is tied to agglomeration of the soil particles bonded together by oil film to form a larger but weakly bonded soil matrix which initially resisted the impact of the loading but thereafter failed with increase in oil content which has weakened the interstitial force of cohesion between the soil particles (Oluremi et al., 2015). Crude oil is rich in hydrogen, and when in contact with soil particles there may be an exchange of divalent ions of the soil particles by monovalent hydrogen ions of the crude oil, which may weaken the soil, giving rise to decrease in unconfined compressive strength. Ratnaweera and Megoda (2006) further attributed the observed reduction in shear strength and stress-strain behaviour of clay soils to a combination of two mechanisms; (a) reduction in frictional properties at particle contacts resulting from changes in mineral-pore fluid-mineral interactions which might be due to the lubrication occurring at particle contacts leading to reduction in maximum post consolidation pressure, (b) changes in the physiochemical interaction which results from changes in the dielectric constant of the pore fluid. According to Gens (2001), with increasing amount of oil in the soil, the degree of pore fluid saturation increases, leading to reduction in soil strength. Between the particles of cohesive soils, are inner cohesive forces responsible for their shear strength. It has been noted that the presence of sand particles in cohesive soils inhibit the cohesiveness of the Kaolinite plate resulting in weakly developed structure which gets weaker in strength (Resende et al., 2005).

Viscosity, surface tension and dielectric constant of oil are factors affecting the compaction characteristics of oil-contaminated soils (Meegoda et al. 1998). The initial increase in MDD is attributed to the lubricating effect of the oil. The viscosity of the crude oil is higher than that of water; therefore as the pore fluid changes from water to crude oil, it tends to lubricate the soil. During compaction, high viscous fluids provide good lubrication 
for the soil particles, which was used to overcome the inter-particle forces and slide against each other to produce better compaction characteristics. Increase in MDD is due to the lubricating action resulting from the addition of crude oil into the soil, which facilitates compaction and reduces the amount of water needed to reach MDD (Al-Sanad et al., 1995). However, the lubricating effect ebbed out at oil content above $4 \%$ when the soil particles were fully coated with oil, which occupied the void spaces hindering the compaction process. This indicates that too much oil is already present in the soil to achieve effective compaction. Jonathan (2013), opined that the crude oil covered the points of contact on the clay molecules that were frequently taken up by water molecules with more stable ions thereby affecting the engineering performance of the soil and reducing the desire of clay for dissociating water molecules, thus resulting in increase in the time it will take for clay soils to compact, and the soil will require more compactive effort to reach its desired compaction. Furthermore, the decrease in MDD is attributable to the lower dielectric constant of crude oil compared to water. Different soil structures are formed when soils are contaminated with organic liquids. This is due to the physico-chemical interactions of soil-liquid system. With lower dielectric constant of a pore fluid, a weaker physico-chemical interaction is established which causes soils to exhibit dispersed structure which reduces the dry density of the soil (Rasheed, 2014). Khamehchiyan et al. (2007) stated that increase in oil content reduces the contact of soil particles and water thus reducing the capillary tension force. This results in a decrease in the MDD of the soil. In addition, Al-Rawas et al. (2005) suggested that oil contamination and presence of water caused separation of voids, resulting in reduction in MDD. Moreover, Akinwumi et al. (2014) tied the drop in MDD to the hydrophobic nature of crude oil. The oil coats itself around the individual clay particles, restricting the contact between particles in soil and water, thereby reducing the density of the soil. Furthermore, Ukpong and Umoh (2015) aligned the reduction in MDD with the absorption of higher molecular weight components into the soil, which caused wettability to change from water-wet to oil-wet. This created an adsorbed layer around the soil particles that is not water soluble and not displaced by water. The oil coats and agglomerates the soil particles thereby reducing the specific surface area and in turn reduces the MDD. Oluremi et al. (2015) also mentioned that alteration of the morphological state of the clay minerals, which act as binding medium in the soil due to presence of organic fluids results in a dispersed structure responsible for the drop in MDD of the soil.

Pore clogging and high viscosity of oil are possible reasons for the decrease in hydraulic conductivity of contaminated soil (Park et al., 2006). It is believed that as the curing time increased the viscosity of the oil also increased resulting in reduction in the pore volume of the soils due to trapped crude oil within the soil particles. In addition, the continuous interaction between the soils and crude oil may have brought about shifts in pore shapes and size distributions due to dynamic kneading resulting in reduced connected voids. Dragun (1998) and Rao and Mathew (1995) also attributed the decrease in $\mathrm{HC}$ to dispersion and deflocculation of clay. Furthermore, Mitchell (1993) indicated that the HC of clays can be strongly influenced by the clay-fluid system interaction. The thickness of the diffused double layer (DDL) is an important controlling factor for the structural development, hydraulic conductivity and other physicochemical and mechanical properties of the soil (Fukue et al., 1999). Van Olphen (1963) opined that the thickness of the DDL around clay particles is controlled by the concentration of salt and type of cation(s) in the soil water. Arasan (2010) also noted that the thickness of the DDL might be influenced by some factors including the dielectric constant of the medium, cation valence, concentration of electrolytes etc. According to the GouyChapman theory, the thickness of the DDL decreases as the ion concentration increases, resulting in flocculation of the clay particles and larger pore channels through which flow can occur (Gleason et al., 1997 and Kaya and Durukan, 2004).

Furthermore, in the double layer theory, Mitchell (1993) maintained that a decrease in fluid's dielectric constant decreases the thickness of the double layer. Therefore, the increase in permeability may be attributed to the reduction or shrinkage of the double layer surrounding the clay particles, which is caused by the reduced dielectric constant of crude oil, compared to that of water. As the soil shrank, micro pores and cracks were formed, giving rise to increase in $\mathrm{HC}$ of the soils. Bowders and Daniel (1987) further suggested that reduction in the thickness of DDL as a result of contamination causes the soil skeleton to shrink, resulting in a decrease in repulsive forces, flocculation of clay particles and dehydration of interlayer zones of expandable clay that becomes gritty or granular. As the repulsive forces decreased, the soil particles tends to flocculate and form aggregates due to attractive forces among particles, leading to a net increase in the effective flow area (Kaya and Fang, 2000). Badv and Omidi (2007) explained that increase in permeability may be due to the contraction of double layer and increased pore spacing resulting from the adsorption of divalent cations into the soil matrix. Compaction of the soil may have engendered cracking of the weak substrate of the soil resulting in the formation of new macro pores with high permeability (Oyediran and Olalusi, 2017). Also, the dissolution of clay minerals in the soil by crude oil as the pore water is replaced by crude oil may also have led to increase in pore spaces, hence increase in

The variation of Quartz and Kaolinite in the presence of crude oil in the soil resulted in an inverse relationship. As the quartz content increased, the Kaolinite content on the other hand decreased. The samples with the highest concentration (10\%) of crude oil suffered the largest loss in Kaolinite content with a corresponding largest increase in Quartz content. Resende et al. (2005) opined that the presence of sand (which is associated with Quartz) particles in cohesive soils inhibit the cohesiveness of the Kaolinite plate resulting in weakly developed structure which gets weaker in strength. Therefore, the inverse relationship between Quartz and Kaolinite as observed in this study supports the trend of variation in the unconfined compressive strength (UCS) of the studied soils where samples with high quartz and low kaolinite content tend to exhibit lower UCS values compared to those with low Quartz and high Kaolinite. The oxide composition indicates that the $\mathrm{SiO}_{2}$ content accounts for the quartz and sand size fraction present in 
the soil while the $\mathrm{Fe}_{2} \mathrm{O}_{3}$ may not be unconnected with hematite. Kostecki and Calabrese (1991) noted that crude oil contains a number of heavy metals such as nickel, vanadium, zinc, lead etc. that may form new compounds when in contact with soil minerals leading to changes in the thickness of the diffused double layer of the soil. The alteration in mineralogical and chemical composition of the soil is believed to have contributed immensely to the varied responses observed in the geotechnical properties of the studied soils

The most abundant mineral in the soil is Kaolinite. This is attributable to weathering of aluminium silicate minerals like feldspar in parent materials. The abundance of Kaolinite in the soil implies that the clay will exhibit low to moderate shrinkage on drying and low to moderate expansion on wetting (Oyediran and Olalusi, 2017). Furthermore, high Kaolinite content in the soil may be associated with well-drained environment and low swelling potential. Mesida (1985) mentioned that the amount and type of clay minerals present in soils affect their geotechnical properties. High swelling clays such as the smectites are more prone to mineral transformation and collapse than mixed clay mineral assemblages and the low swelling Illite and Kaolinite clay groups (Batchelder and Cressey 1998). Quartz is known to be resistant to chemical weathering, its presence accounts for the sand content of the soil while the occurrence of hematite in the soil may not be unconnected with the environment of deposition of the soil.

\section{CONCLUSIONS}

Variations in the geotechnical properties of crude oil contaminated Lateritic clay soils with emphasis on the effects of curing environment and time have shown varied responses which are attributable to the different mineralogical and chemical compositions of the soil, the lubricating effect of the oil, expansion of the diffused double layer of the soil, and replacement of the soil pore fluid by crude oil. This is in addition to the increased contact time of the oil with the soil.

For the unexposed samples, the LL, and PL increases as COC increased up to $4 \%$, above which both decrease, but the reverse was the case for $\mathrm{PI}$ after curing for 21days. With increase in the curing time to 63 and 189 days, LL and PL both increase with increase in COC while PI decreased. The UCS increase with increase in oil content up to $4 \%$, but decreased as oil content increased above 4\%. Furthermore, UCS decreased with increase in curing time. Across all curing periods, MDD increased upon addition of crude oil up to $4 \%$, thereafter it decreased with increase in amount of oil. The hydraulic conductivity decreased with increase in crude oil concentration and time.

For the exposed soils, LL, PL and PI all increased upon addition of crude oil up till $4 \%$ before decreasing as the amount of oil increased above $4 \%$ for the curing duration of 21days. For 63 and 189 days, LL and PL decreased while $\mathrm{PI}$ increased. UCS increased with increase in amount of oil and time. Maximum dry density (MDD) showed same trend of variation as the unexposed samples. Hydraulic conductivity increased with increase in amount of crude and curing time.

The study attempted to mimic and simulate field situation/condition while comparing it with laboratory situation to ascertain the influence of environmental factors and oil-soil contact time on a contaminated soil. The results of this study will be useful to engineers who may want to consider reuse or application of crude oil contaminated soils for any construction purpose as it is unsafe to use such soils without understanding the alterations that have taken place in their engineering properties. The geotechnical properties of crude oil contaminated unexposed clays (confined to room temperature) is far from mimicking in-situ conditions and hence results obtained must be carefully considered. Conclusively, crude oil is capable of modifying the geotechnical properties of soils in contact with it. Furthermore, contaminated soils exposed to the open air and longer curing time are significantly modified than the unexposed soils.

\section{ACKNOWLEDGEMENTS}

The authors duly appreciate the efforts and numerous contributions of Messers Kehinde Adebayo, Daniel Mamedu, Ogeneruru Wekpe and Nwachukwu David towards the success of this work.

\section{REFERENCES}

Adejumo T. E., 2012. Effects of crude oil contamination on the geotechnical properties of soft clay soils of Niger Delta region of Nigeria. EJGE, Vol. 17

Akinwumi I. I., Diwa D. and Obianigwe N., 2014. Effects of crude oil contamination on index properties, strength and permeability of lateritic clay. International Journal of Applied Science and Engineering Research, 3(4): 816-824.

Akinwumi I. I., Maiyaki U. R., Adubi S. A., Daramola S.O. and Ekanem B. B., 2015. Effects of waste engine oil contamination on the plasticity, strength and permeability of lateritic clay. International Journal of Science and Technology Research, 3(9): 331-335.

Al Rawas A., Hassan H. F., Taha R., Hago A., Al Shandoudi B. and Al - Suleimani Y., 2005. Stabilization of oil contaminated soils using cement and cement by - pass dust. Management of Environmental Quality, 16: 670 -680 .

Alsanad H. A., Eid W. K. and Ismael N. F., 1995. Geotechnical properties of oil contaminated Kuwati sand. Journal of Geotechnical Engineering, 5: 407-412.

American Petroleum Institute 2011. API Specification for Materials and Testing for Petroleum Products. API Production Dept. API 14A, Eleventh edition. Dallas: 20-21. AOAC (1984) Official Methods Analytical Chemistry 10th ed: 79-81.

Arasan S., 2010. Effect of chemicals on geotechnical properties of clay liners: A review. Research Journal of Applied Sciences, Engineering and Technology, 2(8): $765-775$.

Badv K. And Omidi A., 2007. Effect of synthetic leachate on the hydraulic conductivity of clayey soil in 
Urmia city landfill site. Iran journal of Science and Technology, 31(B5): 535-545.

Batchelder M. and Cressey G., 1998. Rapid, accurate phase quantification of clay-bearing samples using a position-sensitive X-ray detector. Clays Clay Miner, 46(2): 183-194.

Bowders J. J. and Daniel D. E., 1987. Hydraulic conductivity of compacted clay to dilute organic chemicals. ASCE Journal of Geotechnical Engineering, 113(12): 1432 - 1448.

Broderick G. P. and Daniel D. E., 1990. Stabilizing compacted clay against chemical attach. Journal of Geotechnical. Engineering, 116(10): 1549-1567.

BS 1377 1990. Methods of tests for soils for Civil Engineering purposes. British Standard Institution, London.

Das B. M., 1994. Principles of Geotechnical Engineering, third ed., PWS Publishing Company, 436p.

Dragun J., 1998. The soil chemistry of hazardous materials. Amherst Scientific Publishers, ISBN 1884940110, 9781884940118, 862p.

Evgin E. and Das B. M., 1992. Mechanical behavior of an oil contaminated sand. In: Usmen, Acar (Eds.), Environ. Geotechnology Proc., Mediterranean Conference. Balkema Publishers, Rotterdam, The Netherlands, pp. 101-108.

Friedman G. M. and Sanders J. E., 1997. Principles of Sedimentology. John Wiley and Sons: New York, NY. 792p.

Fukue M., Minato T., Horibe H. and Taya N., 1999. The Micro - structures of clay given by resistivity measurements. Eng. Geol., 54: 43 - 53.

Gens A., 2001. Soil - environment interactions in geotechnical engineering. Journal of Geotechniques. 24(4): $627-640$.

Gleason M. H., Daniel D. E. and Eykholt G. R., 1997. Calcium and sodium bentonite for hydraulic containment applications. Journal of Geotech. Geoenviron. Eng., 123(5): 438 - 445

Iloeje A. F. and Aniago V., 2016. Effect of crude oil on permeability properties of the soil. International Journal of Trend in Scientific Research and Development, 1(1): 39 - 43.

Jesna J. and Hari G., 2015. Investigation on the effects of hydrocarbon spillage on soil properties. International Journal of Engineering Research and Technology, 4 (10): 136-140.
Jonathan O. O., 2013. The effect of light crude oil contamination on the geotechnical properties of kaolinite clay soil. Unpublished Ph.D. thesis, Anglia Ruskin University, UK, 345p.

Kaya A. and Durukan S., 2004. Utilization of bentonite embedded zeolite as clay liner. Applied Clay Science. 25: $83-91$.

Kaya A. and Fang H. Y., 2000. Effect of organic fluids on physiochemical parameters of fine-grained soils. Canadian Geotechnical Journal, 37(5): 943 950.

Khamehchiyan M., Hossein C. A. and Tajik M., 2007. Effect of crude oil contamination on geotechnical properties of clayey and sandy soils. Engineering Geology, 89: 220 - 229.

Kostecki P. T. and Calabrese E. J., 1991. A progressive Report on the Council for Health and Environmental Safety of soils (CHESS), in Hydrocarbon contaminated soils and Groundwater. Vol.1. Lewis publishers, Chelsea, Michigan.

Kurt Z. N., Arasan S., Hamutcu U. and Akbulut R. K., 2007. Effect of salt solution temperature on the liquid limit of clay liners in solid waste disposal landfills. Geotechnical Symposium. Adana, Turkey, $383-390$.

Meegoda J. N. and Ratnaweera P., 1994. Compressibility of contaminated fine-grained soils. Geotechnical Testing Journal, 17(1): 101 112.

Meegoda J. N., Chen B., Gunasekera S. D. and Pederson P., 1998. Compaction characteristics of contaminated soils - reuse as a road base material. Recycled materials in Geotechnical applications. Geotechnical Special Publication, Vol. 79: 165- 209.

Mesida E. A., 1985. The Influence of Geological Factors on the Engineering Properties of some western Nigeria Residual Lateritic Soils as Highway Construction Materials. Unpublished Ph.D. thesis, Department of Geology, University of Ife, Nigeria. 193p.

Mitchell J. K., 1976. Fundamentals of soil behaviour. John Wiley, New York.

Mitchell J. K., 1993. Fundamentals of soil behaviour. $2^{\text {nd }}$ Ed., John Wiley and Sons Inc. New York.

Moore C. A. and Mitchell J. K. (1994). Electromagnetic forces and soil strength. Journal of Geotechniques, 24(4): 627 - 640 .

Ojuri O. O. and Ogundijo O., 2012. Modelling Used Emgine Oil Impact on the Compaction and Strength Cgaracteristics of a Lateritic Soil. Electronic Journal of Geotechnical Engineeing, $17(\times) 3491-3501$ 
Oluremi J. R., Adewuyi A. P. and Sanni A. A., 2015. Compaction characteristics of oil contaminated residual soils. Journal of Engineering and Technology, 6(2): $75-87$.

Oluremi J. R., Yahanna P. and Akinsola S. O., 2017. Effect of compactive efforts on geotechnical properties of spent engine oil contaminated lateritic soil. Journal of Engineering Science and Technology, 12(3): $596-607$.

Otunyo A. W., 2010. Reduction of the shear strength of soils in the Niger delta area of Nigeria due to crude oil production. Nigerian Journal of Technology, 29(2): $130-140$.

Oyediran, I. A. and Enya, N. I., 2020. Crude oil Effects on Some Engineering Properties of Sandy Alluvial Soil. International Journal of Mining and Geo-Engineering.

DOI:10.22059/ijmge.2020.283051.594815

Oyediran I. A. and Olalusi D. A., 2017. Hydraulic conductivity and leachate removal rate of genetically different compacted clays. Innovative Infrastructure Solutions, 2(46): 1-14.

Park J., Vipulanandan C., Kim J. W., and Oh M. H., 2006. Effects of surfactants and electrolyte solutions on the properties of soil. Environmental Geology, 49: 977 - 989.

Rao S. N. and Mathew P. K., 1995. Effects of exchangeable cations on hydraulic conductivity of marine clay. Clays and Clay Mineralogy, 43(4): $433-437$
Rasheed Z. N., Ahmed F. R. and Jassim H. M., 2014. Effect of crude oil products on the geotechnical properties of soil. Journal of Energy and Sustainability. Vol. 186: $354-362$.

Ratnaweera P. and Meegoda N. J., 2006. Shear strength and stress - strain behaviour of contaminated soils. Geotechnical Testing Journal, 29(2): $133-140$.

Resende M., Curi N., Ker C. J. and Rezende S. R., 2005. Mineralogia de Solos Brasileiros interpretacoes e aplicacoes. Lavras: Editora UFLA, 192p.

Shin E., Lee J. and Das B. M., 1997. Geotechnical properties of crude oil contaminated sand. Proceedings of the international offshore and polar engineering conference ISOPE, GOLDEN, USA, 1: 946 - 949.

Ukpong E. C. and Umoh I, C., 2015. Effects of crude oil spillage on geotechnical properties of lateritic soils in Okoroete, Eastern Obolo. International Journal of Engineering and Applied Sciences, $7(1): 10-24$.

Van Olphen H., 1963. An introduction to clay colloid chemistry. $1^{\text {st }}$ Ed. John Wiley and sons, New York

Yaji, R. K., Ramakrishnegowda C. and Thomas P. C., 1997. Change in behavior of shedi soil due to contamination. I.G.C - 1997 Vadodar

Appendix 1: Details of geotechnical, chemical and mineralogical parameters for unexposed contaminated soils

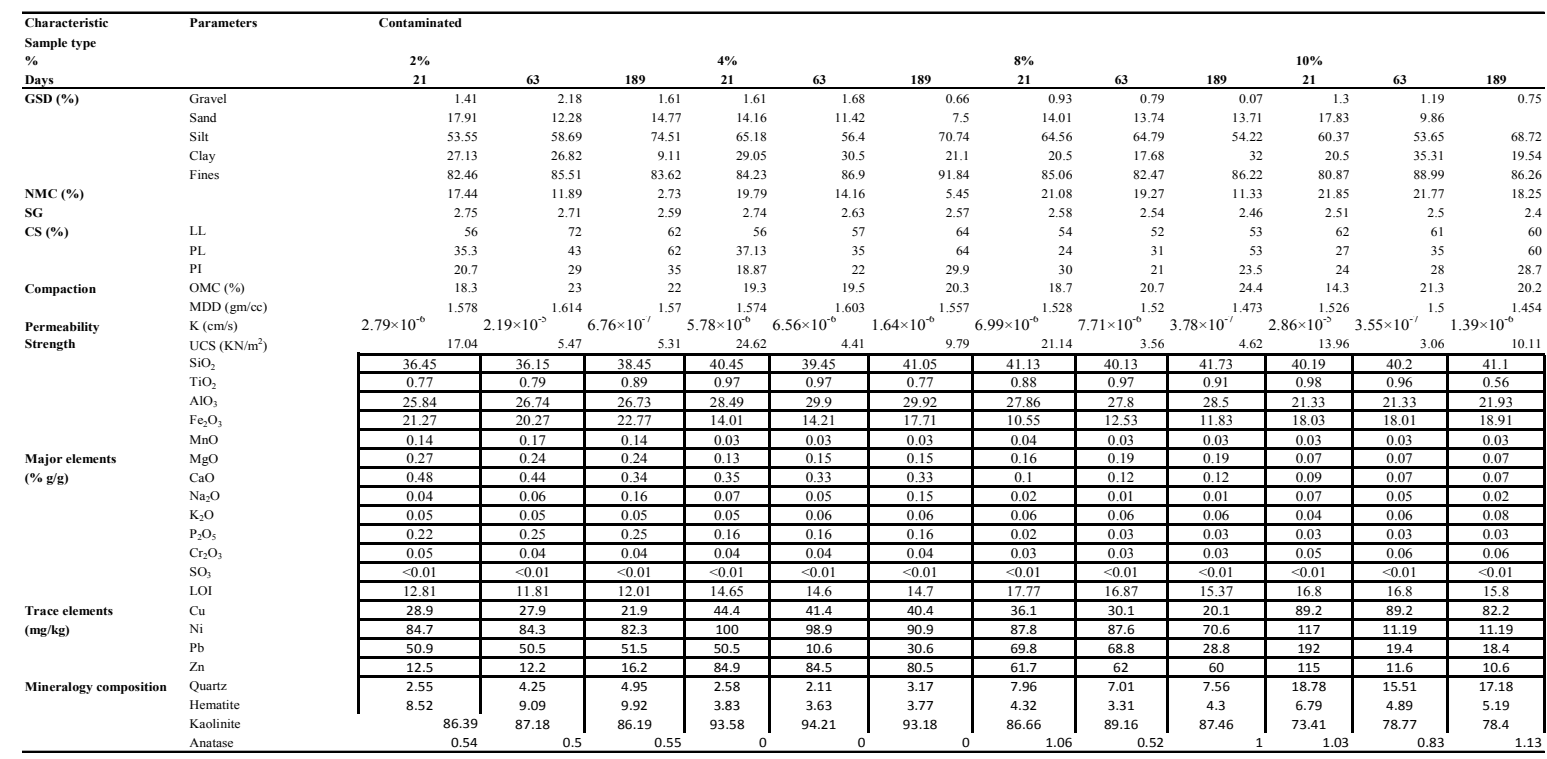


Appendix 2: Details of geotechnical, chemical and mineralogical parameters for exposed contaminated soils

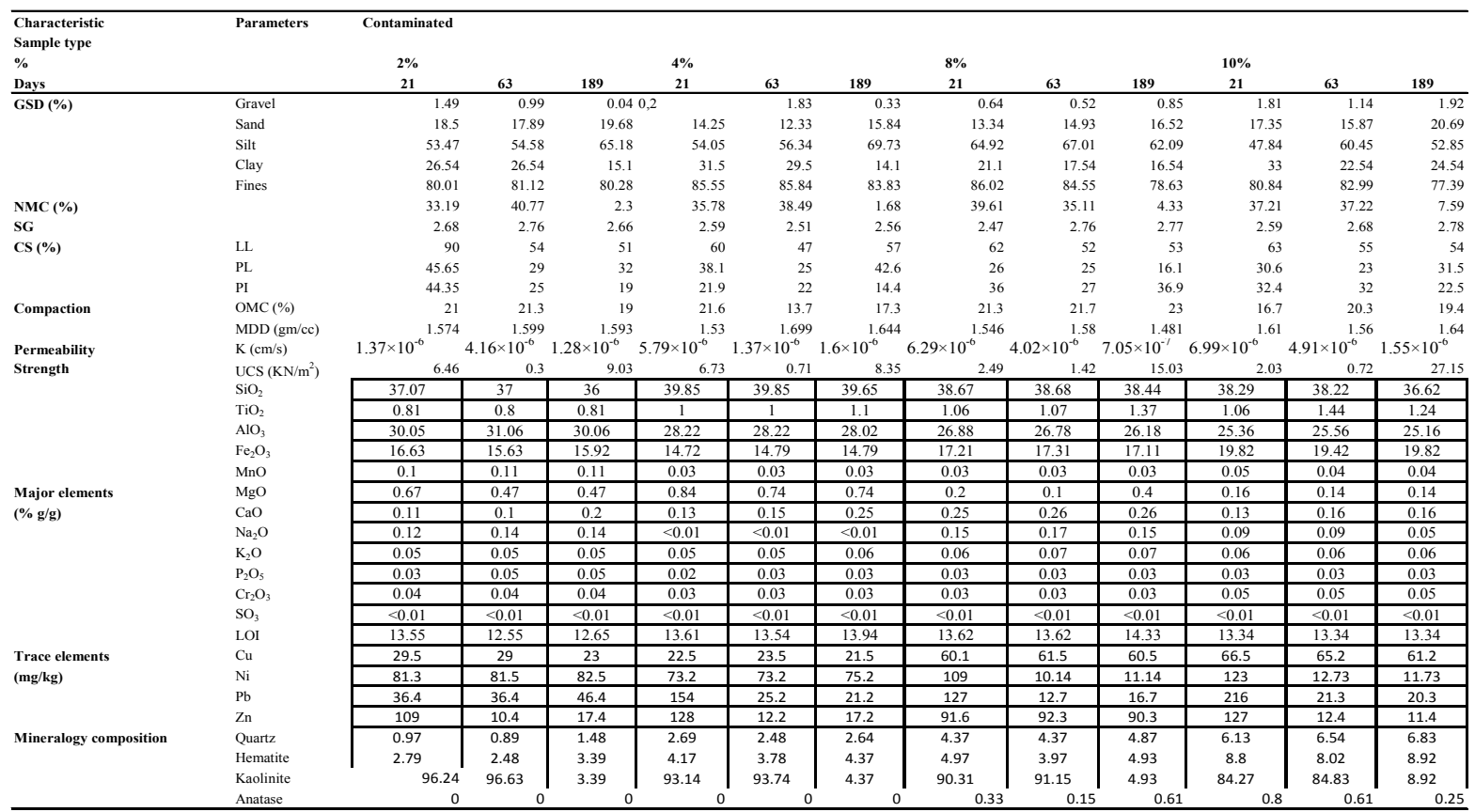

